\title{
Challenges experienced by nurse educators on the delivery of content laden curriculum at a nursing college in Gauteng
}

\author{
Maria Gugu Ndawo * \\ Nursing Department, University of Johannesburg, Auckland Park, South Africa
}

Received: April 1, 2015

DOI: $10.5430 /$ jnep.v5n11p103

\author{
Accepted: June 10, 2015 \\ Online Published: August 24, 2015 \\ URL: http://dx.doi.org/10.5430/jnep.v5n11p103
}

\begin{abstract}
Objective: Nursing education is characterised by content laden curriculum which results in superficial coverage of content by most nurse educators in order to get the curriculum finished. The aim of this study was to explore and describe the challenges experienced by nurse educators on the delivery of content laden curriculum at a nursing college in Gauteng.

Methods: A purposive sampling was used to select 20 nurse educators who teach a four-year comprehensive nursing diploma at a nursing college in Gauteng. The data were collected through audio-taped, in-depth, semi-structured individual interviews until data saturation was reached. The study was enriched with field notes that were taken to increase the credibility of data collected. Data were analysed by the researcher and an independent coder using Tesch's protocol of qualitative data analysis. Trustworthiness was ensured through the use of Lincoln and Guba's four principles.

Results: The findings revealed that the challenges experienced by nurse educators during delivery of content laden curriculum were large classes, academically underprepared learner nurses, lack of learner nurses' prior knowledge and learner nurses' negative attitude towards nursing. Following these findings, the implications of the results were discussed and recommendations were made that can be used to facilitate effective delivery of the content laden curriculum.

Conclusions: The findings from this study suggest that the need to cover the learning content should not supersede effective teaching and meaningful learning for the development of higher-order thinking skills in learner nurses.
\end{abstract}

Key Words: Challenge, Content laden curriculum, Academic underpreparedness, Prior knowledge

\section{INTRODUCTION}

The four-year comprehensive nursing diploma programme is heavily laden with the learning content. This is in response to the emerging disease profile and lifestyle of the South African community as the country faces a quadruple burden of disease such as HIV and AIDS; communicable diseases; non-communicable diseases; and violence and injuries resulting in high levels of morbidity and mortality. ${ }^{[1]}$ For example, it was estimated in 2012 that $12.2 \%$ that is 6.4 million persons of the population were HIV positive, which is 1.2 million more people living with HIV than in 2008 when at the time they were $10.6 \%$ totalling 5.2 million. ${ }^{[2]}$ Although, over the past ten years the learning content of this programme increased, the prescripts of the four year duration of delivery stipulated by the South African Nursing Council (SANC) Regulation 425 of 1,985 (as amended), ${ }^{[3]}$ however, remained the same. In accordance with this regulation, learner nurses have four specialties upon completion Africa.

*Correspondence: Maria Gugu Ndawo; Email: gugun@uj.ac.za; Address: Nursing Department, University of Johannesburg, Auckland Park, South 
of the nursing programme namely: general nurse, psychiatric nurse, community nurse and midwife, which renders it "comprehensive". The motivation behind this four-year comprehensive nursing diploma programme which commenced in 1985 was to prepare a professional nurse who is a generalist, who could also provide care to psychiatric patients within the general health system, as well as practice in a community setting should they choose to.

This programme was also thought to be more cost-effective, since this professional nurse with four specialties was prepared in four years at a learner nurse-level cost whereas in the past and prior to the commencement of this programme, a general nurse trained for three years and only could then obtain the three additional qualifications (midwifery, community health nursing and psychiatric nursing) at one year for each, making the total time six years for all specialties. ${ }^{[4]}$ Whilst the programme alone is content laden, the burden of the diseases mentioned makes it more heavier as there is lack of evidence of the removal of the content that no longer apply in today's practice yet the aim of nursing education is to provide adequate numbers of highly competent, caring nurses who are well equipped to deal with the current health needs of the country. ${ }^{[5]}$

The delivery of this content laden curriculum poses a major challenge for nurse educators in implementing different teaching methods to learner nurses in the classroom. Therefore, to cover the content, most nurse educators rely on the traditional lecture method to teach learner nurses at the nursing college under study. With this type of instructivistic teaching, learner nurses experience frustration, they are overwhelmed with this excessive content that they must learn, there is excessive reading assignments, content processing, and memorization. ${ }^{[6]}$ The transformation of nursing education to the information age, constant changes in health care delivery system, educator-centred pedagogical approaches, content repetition and the academic-practice gap compound the already existing, large content. Yet, changes in nursing education to keep up with these compounding factors are much slower. ${ }^{[6]}$ Nurse educators are challenged and need to seek alternative interactive methods of teaching and assessment in order to work through the curriculum and still produce critical, reflective and creative thinkers who will be able to render effective comprehensive care to culturally diverse communities.

\subsection{Problem statement}

As a result of a content laden curriculum, most nurse educators feel the enormous pressure to cover the learning content that they teach in class in order for learner nurses to be successful in their examinations and become the much needed professional nurses. ${ }^{[7]}$ However, delivering heavily laden content to learner nurses without empowering them with the acquisition of knowledge and essential skills subjects them to academic failure, and those who succeed academically have difficulties thinking critically, solving ill-defined, complex problems and making rational decisions regarding patients' conditions. In that way they become the weakest link within the multi-disciplinary environment, and yet they are the members of the multi-disciplinary team that spend the most time with the clients. ${ }^{[8]}$ This is confirmed by Benner, Sutphen, Leonard and Day, ${ }^{[9]}$ who state that professional nurses entering the field lack the essential skills and knowledge for holistic nursing care and practice. The major challenges with the delivery of the heavily laden content are the dominant use of the lecture method, lack of active learning by learner nurses, inability to develop learner nurses' critical thinking, analysis and problem solving skills, and inability to prepare learner nurses to deal with patients' real-life ill-defined, complex problems. ${ }^{[10]}$ Nurse educators in the nursing college under study face many other challenges associated with the delivery of the content laden curriculum, understanding these challenges was then necessary for recommendations to be made in order to facilitate effective learning in learner nurses. The following research questions guided the study:

- What are the experiences of nurse educators regarding the delivery of content laden curriculum at a nursing college in Gauteng?

- What can be done to facilitate the effective delivery of the content laden curriculum at this nursing college?

\subsection{Research aim and objectives}

In accordance with the problem statement, the aim of this study was to explore and describe challenges experienced by nurse educators on the delivery of content laden curriculum at a nursing college in Gauteng in order to describe recommendations to facilitate effective delivery of the content.

\subsection{Definitions of key concepts}

Challenge is a new or difficult task that tests someone's ability and skill. ${ }^{[11]}$ Challenges in this study refer to difficult situations encountered by nurse educators during the delivery of content laden curriculum in class.

Experience is the knowledge that comes from being personally involved in an event, situation or circumstance. ${ }^{[12]}$

Nurse educator in this study is a person who is registered with the SANC, possesses a degree or a diploma in nursing education in accordance with Regulation 118 of 1987 as stipulated in the Nursing Act, ${ }^{[13]}$ and is an employee of a nursing college in Gauteng. 
Content laden curriculum is a curriculum loaded with content and facts to be memorised, in a mostly passive learning environment. $^{[14]}$

Nursing college is a post-secondary education institution that offers professional nursing education at basic and postbasic level where such nursing education has been approved in terms of section 15 (2) of the Nursing Act. ${ }^{[13]}$ In this study a nursing college refers to a specific college situated in Gauteng.

\section{METHOD}

\subsection{Design}

A contextual, qualitative, exploratory and descriptive design was employed to conduct the phenomenological, individual, semi-structured interviews. Qualitative research provides an opportunity aimed at gaining a detailed and deeper understanding of the phenomenon. The researcher explored and described the challenges experienced by nurse educators on the delivery of content laden curriculum at a nursing college in Gauteng.

\subsection{Population and sampling}

The accessible population for this study consisted of 104 nurse educators who teach subjects of the four-year comprehensive nursing diploma programme leading to registration as a nurse (general, psychiatric and community) and midwife as stipulated by SANC Regulation 425 of 1,985 (as amended $)^{[3]}$ at a nursing college in Gauteng. The target population consisted of nurse educators who consented and volunteered to participate in the study and who taught a class of more than 450 first year learner nurses in one class session. The sample in this study consisted of 20 nurse educators who were purposively selected because they possessed rich and in-depth data, and the researcher learned a great deal about challenges regarding the delivery of content laden curriculum in class from them. Permission to conduct a research study was obtained from the Academic Ethics Committee of a University (Ref: AEC 43-01-2012), the Department of Health and the nursing college under study.

\subsection{Data collection}

In order to collect data, the researcher used semi-structured individual interviews, conducted in English between January and February 2013, in which participants were allowed maximum opportunity to tell their story. The interviews, which lasted for 45 to 60 minutes, were conducted by the researcher and field notes were collected to enrich the data collected. All nurse educators consented to and voluntarily participated in the study. The interviews were conducted in participants' offices at a time that was chosen by each participant. The researcher ensured that no teaching and learning activities were disrupted in order to conduct the interviews.

The research question that guided the interviews was: "What challenges do you experience during the delivery of content laden curriculum in your classroom at this nursing college?" To ensure the detailed exploration of data, communication clarification techniques such as probing, summarising, listening, silence, paraphrasing and focusing were used. All interviews were audio-taped with the participants' permission in order to increase credibility of the study, and to provide the researcher an opportunity for intensive analysis of the collected data. The information was transcribed verbatim as soon as possible after interviews.

\subsection{Data analysis}

Data analysis entailed categorising, ordering, summarising the data and describing it in meaningful terms. A thematic analysis was done of the recorded interviews using Tesch's protocol of qualitative open-coding technique. ${ }^{[15]}$ Open coding was conducted manually by the researcher. A theme emerged and data were further reduced into subthemes to construct deeper levels of meaning of the phenomenon under study. A consensus discussion meeting was held with an independent coder and an agreement was reached regarding the emerged theme and subthemes. Follow-up interviews with twelve participants were organised to verify the theme and subthemes. The identified theme and subthemes were conceptualised within the existing relevant literature.

\subsection{Trustworthiness}

The researcher used Lincoln and Guba's ${ }^{[16]}$ method of establishing trustworthiness in qualitative studies to ensure credibility, dependability, confirmability and transferability of the study. Credibility was ensured through the use of prolonged engagement, triangulation, member checking and referral adequacy. Prolonged engagement was ensured by spending sufficient time with the participants prior and during the interviews, as well as by building trust through honouring anonymity. Triangulation was achieved by using multiple data collection methods and taking field notes. Member checking was ensured through going back to eight of the participants, to ascertain whether the transcribed data was a truthful version of their experiences. Referral adequacy was ensured through audio-tape recording the interviews, taking field notes and verbatim transcriptions of each interview.

Dependability was achieved through a dense description of the research methodology used to conduct the study, and a dense description of the data collection and interpretation. The researcher and independent coder held a meeting to reach consensus on the theme and subthemes that emerged 
throughout the interviews. The raw interview data, field notes, verbatim transcriptions, findings, interpretations and recommendations were kept in a safe place, and were made available and accessible to the researcher and independent coder for the sole purpose of keeping an audit trail. Confirmability was ensured by keeping an audit trail of the verbatim descriptions, and subthemes that emerged to show what transpired during the research process. Transferability was ensured through literature control after the collection of the data, during which similar findings of other research studies were integrated. Purposive sampling was used to select the participants. A dense description was made of the research methodology and the research process in order to enable other researchers interested in replicating the study to reach similar conclusions.

\subsection{Ethical considerations}

The right of self-determination to choose to participate in the study, the right to privacy of information and the right to autonomy and confidentiality by handling the information anonymously were adhered to. ${ }^{[12]}$ Informed consent from participants was obtained after a thorough explanation of the purpose, objectives and method of the study, participants' expectations and that participation is purely voluntary. Participants were informed that they have the right to withdraw from the study at any time without any penalties.

\section{RESULTS AND DISSCUSSION}

All participants stated that the comprehensive nursing programme is heavily laden with the learning content that is condensed so that it fits into the four-year time frame and it results to a lot of information that learner nurses need to learn in these four years. The themes that emerged as compounding challenges experienced by the participants were delivery of content laden curriculum to: large classes, academically underprepared learner nurses, learner nurses who lack prior knowledge and learner nurses' with negative attitude towards nursing. These findings are discussed and supported by direct quotations from participants, and conceptualisation within existing relevant literature was done to be able to derive recommendations to deal with these challenges.

\subsection{First theme: Delivery of content laden curriculum to large classes}

Large classes were a major challenge that was experienced by most nurse educators. Of a major concern was the disruptive behaviour displayed by learner nurses in a large class such as talking to each other, on their mobile phones and others sleeping. The large class size made it difficult for them to deliver the heavily laden content since large classes did not afford them time to allow learner nurses to engage with the learning content. Teaching in an auditorium with fixed chairs made it difficult for them to navigate between the large groups of learner nurses and as a result the most engaged and interactive learner nurses are those who sit in the front rows whilst other learner nurses in the rear rows were being disruptive. When disruptions occur, nurse educators found it difficult to deliver the content laden curriculum effectively and efficiently. The following direct quotations from nurse educators illustrate their experiences of delivering heavily laden content to a large class of learner nurses:

"Remember, the auditorium is full of learners. There are those that are just talking to each other and having serious conversations, and there's that one who just leaves. Others are fidgeting on their cell phones, whilst others are surfing the internet and others sleeping. At the end of the day you must finish the content and ensure comprehension in the allocated time slot but it is impossible". (Participant 15)

"When the class is large, they [students] are afraid to ask questions in front of the other students because they are not comfortable but that means that whatever content you are teaching them they do not grasp and that also means it piles up." (Participant 8)

"In most instances because the group is so large, the students that are attentive are the ones sitting in front, whilst the rear is more disruptive and noisy. Unfortunately, you wouldn't know how far the noise reaches." (Participant 2)

"It is very challenging for you as a lecturer when you have SO (emphasised) much content to teach to SO (emphasised) many students. It makes you choose the one aspect that you can actually manipulate, which at the end of the day becomes the large content. So you just deliver it at the speed of light in order for you to make sure that you are finished with your syllabus." (Participant 16)

"The large number of students impacts on the type of teaching instructions you are going to use in order to deliver the large content. As a result we simply use the lecture method to teach the students in order to cover the content, regardless of whether they understand the learning content or not." (Participant 3)

"Outcomes-Based Education [system] can't be practiced. All the advocated teaching strategies are good and well, but they are impossible to implement in order to deliver the large content due to large group[s] of students... and the use of auditoria (sounding stressed)." (Participant 4) 
According to Tripod, ${ }^{[17]}$ a large class is one in which nurse educators can no longer cope with the number of learner nurses, even if they have a desire to provide individual attention to the learners. In this study a large class refers to a class of about 450 learner nurses in the first year of study taught together in an auditorium. The large classes have negative effects on nurse educators and learner nurses such as the predominant use of the lecture method by nurse educator which ignores active learning by learner nurses, disengagement of learners with the learning content inside and outside of the large class, lack of development of higher order thinking skills in learner nurses, minimal learner-educator interaction and lower learner academic achievement. ${ }^{[18,19]}$ These remarks strongly suggested that within a large class during delivery of the content laden curriculum, nurse educators experienced uncivil behaviour from learner nurses which highlighted the extent to which nurse educators are unable to finish the laden content meaningfully. The role of a nurse educator is to create an enabling learning environment that facilitates effective and meaningful delivery of the learning content and uncivil learner behaviour may hinder nurse educators' ability to create and manage such environments. ${ }^{[20]}$ Nurse educators were also overwhelmed by the large classes as well as the heavily laden content that they placed more emphasis on covering this content through the predominant use of lecture method than on facilitating understanding of the content. This is supported by Persky ${ }^{[21]}$ who stated that the learning content of many disciplines with large classes has become too large to master by educators and therefore lecturing dominates in these classes. The experiences of nurse educators with the delivery of content laden curriculum to a large class of learner nurses contributes to the failure to engage learner nurses in interactive pedagogical approaches that develop higher-order thinking skills. Failure to use these approaches result in facilitation of the null curriculum which according to Billings and Halstead, ${ }^{[22] ~ " i s ~ t h e ~ c u r r i c u l u m ~ c o n-~}$ tent and behaviour areas that nurse educators think they are teaching but in fact are not such as critical thinking, reflective thinking, problem solving and decision making".

\subsection{Second theme: Delivery of content laden curriculum to academically underprepared learner nurses}

Nurse educators also expressed that the majority of learner nurses who are in large classes are academically underprepared for higher education in general. This was identified as another challenge that impact on the manner in which the content laden curriculum is delivered in class. Nurse educators' experiences were that learner nurses lack basic reading, writing and arithmetic skills needed in nursing. They were also forced to lower their level of teaching standards so that learner nurses could understand the content, however, this was experienced as time-consuming to ensure that all learner nurses understand the learning content, since they are at different levels of understanding. The following quotes supported this:

"Some of these students lack skills in simple reading and writing. It makes you wonder how they passed their matric. It is very difficult to deliver the large nursing learning content and still have to catch up on these skills in order to help these students grasp the subject content.' (Participant 17)

"Nursing requires that a nurse is able to do basic arithmetic. This is important in the calculations of drugs for the patients especially paediatrics, however, some of our students can't even multiply yet come straight from matric! How are you going to finish your lecture on drug calculation when you must still teach them to do basic calculations? (Flabbergasted)." (Participant 8)

"We are forced to downgrade our level of teaching during the delivery of this condensed learning content so that we also accommodate these students who have difficulties with understanding. This is time-consuming since we must make sure that they understand before moving on, meaning you risk not finishing the large content (raising her voice)." (Participant 12)

"The majority of the students we have in class are just not prepared for intense studying that one undergoes in nursing. These students struggle and they are many, that is why our failure rate is so high. These students simply don't perform because they are not ready for colleges.' (Participant 10)

"At times it's not because these learners are not intelligent, they fail the course in numbers simply because their work is too much and they just don't comprehend it. Remember mam, these students write their own language using their cellphones and are not acquainted with the correct reading and writing. So they fail not because they are stupid or something but because they can't read and write." (Participant 11)

Academic preparedness refers to the knowledge of and skill levels or proficiency in reading, writing and mathematics that are necessary at a higher education institution without remediation $^{[23]}$ whereas academic underpreparedness includes struggling with understanding the higher education curriculum. ${ }^{[24]}$ Academic preparedness is viewed as a strong measure of success in higher education and learners who are underprepared academically are most likely to face academic challenges in their higher education studies. ${ }^{[25]}$ Nurse educators expressed that to understand the content 
laden curriculum that will be delivered in class, a certain level of academic preparedness is expected to be met by prospective learner nurses before being accepted into any nursing programme. However, they experienced that these learner nurses are accepted to a content-laden professional vocational qualification in large classes taught in auditoria being academically underprepared which results in academic failure. Nurse educators also realised that learner nurses in their classes are academically underprepared and this does not imply that they lack the needed intellectual capacity. A large percentage of learner nurses who are in these large classes are academically underprepared, with insufficient proficiency to assimilate the intense heavily laden learning content of the nursing programmes independently. Sadly, this is also confirmed by Mthethwa, ${ }^{[26]}$ a student who was educated at a private school and matriculated with four distinctions, who stated that, despite her privileged education, she was never prepared for the large classes and the heavily laden curriculum. Learner nurses who are admitted into the intense four-year comprehensive nursing diploma programme find themselves immersed in a large class and are expected to demonstrate competency over content laden curriculum, including knowledge and comprehension as well as the application of such knowledge to real-world situations and the development of analytical, synthesis and evaluative skills appropriate to such heavily laden content being delivered. Sometimes, nursing relies on learners who have obtained high admission scores, but who have been found to be academically underprepared to make up its recruitment numbers, leading to high dropout rates in the first year of study. ${ }^{[27]}$

\subsection{Third theme: Delivery of content laden curriculum to learner nurses with lack of prior knowledge}

Nurse educators raised a concern that most of the learner nurses in their large classes did not take nursing-relevant subjects in high school. They stated that most learner nurses did not study Biology, Mathematics and Physical Science at high school which had negative implications for both the nurse educators and learner nurses. They experienced difficulties having to help learner nurses to "catch-up" because they did not possess the required prior knowledge to succeed in the programme. These experiences made effective delivery of the content laden curriculum very challenging for nurse educators. This is evident in the following quotes:

"Imagine in the auditorium (Surprised)! ... Others, it's for the first time that they are hearing of a human cell. So they ask 'Ma'am, what are you talking about, where is that cell as I'm standing?' ... Within these 450 students, some and sometimes most of them were never selected in accordance with the nursing training programme. Then we have a student to whom you are teaching a particular topic ... (Paused) she does not even know what you are talking about. So which means that the student is already behind and in that 45 minutes within which you are scheduled to teach ... she did not understand a word." (Participant 1)

"From grade 9, students at high school choose the subjects to qualifications that they are interested in when they are at varsity. They then carry on with those subjects till matric giving them a head start with these subjects of 4 years cementing this knowledge prior to university. Now you have a student who have done Agriculture in high school, tell me then, how do you bridge the 4 years of Biology that this kid lost at school in just under 1 year (sounding very depressed)?" (Participant 17)

"These are real challenges we face, it is very frustrating. A student who has no knowledge of Biology but you must make sure that they understand it. How, how, how? Where do you start, where do you get the time? Mam, there is more than two hundred of them? Tell me then, HOW? (Placing emphasis)." (Participant 11)

"Biology is one of these subjects. Physical Science and Maths Literacy if Mathematics is difficult are also important subjects to consider during selection. Students should know numbers because in nursing, dosages for medications are calculated according to body weight, patients are ventilated according to body weight and if the student has never encountered calculations in high school it becomes a challenge." (Participant 20)

"Students should have English and Biology as the key subjects; however, that is not the case, because we have students who studied Commerce as the major subject in high school and that was studied from Standard 8/Grade 10 and that student knows nothing about human biology. This make it difficult to teach this condensed content because students do not know and do not understand what you are talking about." (Participant 7)

It is evident from the above statement that nurse educators experienced challenges in delivering the content laden curriculum to learner nurses without basic prior knowledge of the subject. Nurse educators realised that, even though they are teaching learner nurses, at the end of the learning content delivery they did not reach them. There was a sense of despair with regard to how and when they can assist in filling the basic knowledge gap and assist learner nurses in making meaning of the content laden curriculum that is being deliv- 
ered due to the time constraint posed by the nursing college attendance hours (08:00 to 16:00) and the duration of the nursing programme. Prior knowledge conditions learning, and learner nurses' existing knowledge plays a crucial role in the comprehension of new knowledge. The importance of prior knowledge is acknowledged in Ausubel's assimilation theory, which stated that educators must always start their delivery of the new content laden curriculum at the learner's basic subject knowledge level because learners' prior knowledge is the most important single factor influencing learning and achievement through meaning making. ${ }^{[28]}$ Lack of prior knowledge result in difficulty in comprehending the new knowledge presented to the learner nurses hence learning will be inhibited. Nurse educators also stated that lack of prior knowledge placed learner nurses at a disadvantage since they required more attention and time during large content delivery than they can provide. According to Tsai and Tsai, ${ }^{[29]}$ lack of prior knowledge might result in difficulty in using the given assistance for content structure mapping. Implying that even when academic assistance is rendered to learner nurses who do not possess the appropriate prior knowledge, they would still experience challenges in organising and understanding the new, unfamiliar content laden curriculum being delivered. On the contrary, Ofori ${ }^{[27]}$ found that learners who took a Biology subject showed no significant increase in performance in their biological modules and this could be attributed to, amongst others, the intensive tuition. However, the heavily laden learning content is highly abstract, and learner nurses without prior knowledge tend to be educatordependent and lack self-direction and confidence unless they are highly motivated to learn. ${ }^{[29]}$

\subsection{Fourth theme: Delivery of content laden curriculum to learner nurses' with negative attitude towards nursing}

Nurse educators also stated that the majority of learner nurses in large classes have a "bad" attitude towards their studies, with some learner nurses expecting to be pushed to study. Nurse educators perceived that learner nurses have negative attitudes because they are not interested in nursing but are attracted to nursing because of the monthly stipend and high rate of unemployment. This negative attitude impacts on the manner in which they deliver the learning content in class as the majority of learner nurses are not receptive of the learning content.

"Students are studying nursing here and paying their way through to the degree that they wanted in the first place. The student is intelligent enough to pass and is getting $50 \%$, just scraping through. Do you know why? (Sounding irritated). Because nursing is not her priority, she's actually registered with [a distance learning university] for another course and use nursing as a stepping stone and its stipend. You find them sleeping in class because of all the double studying that some are doing." (Participant 8)

"You must first go back to level one and find out why some students came into nursing in the first place. They came into nursing because of the unemployment rate in South Africa. Nursing is not regarded as a profession ... In reverting to what some prominent politicians said during the nurses' strike 'Anybody from the street can be a nurse'. They said anybody can become a nurse. So anybody did become a nurse." (Participant 1)

"As a result of the high unemployment rate in the country, some of the students who might not have money for tertiary fees and some that are varsity drop-outs are using nursing as a fall-back. So we receive such people from the Department of Labour, hence our high failure rate (raising her voice, looking irritated). They do not want to be H.E.R.E!!!! (Drawn out for emphasis)." (Participant 13)

"Most are absent in class, those that are here are absent minded! They do not do their homework, they just don't care and they become very rude at times.)" (Participant 9)

This notion is reiterated by Tayebi, Dehghan-Nayeri, Negarandeh and Shahbazi ${ }^{[30]}$ who, in their study, found that the majority of learner nurses had a negative attitude towards nursing as a career and profession. Globally, most learners chose nursing based on reasons other than wanting to become professional nurses. ${ }^{[31]}$ In South Africa many learners were attracted to nursing because of a salary, stipend or bursary. ${ }^{[32]}$ Nursing has been and continues to be perceived as a job for those who are financially insecure, and is advertised as such by the Gauteng Department of Labour (DoL), as the newspaper headline read "Nursing opportunities for Gauteng job seekers". [33] Some learner nurses came to nursing having a desire to help the sick as a motivational factor. However, Wright and Maree ${ }^{[34]}$ state that this affective factor leads to a lack of realisation that there are cognitive aspects to nursing education. This results in shock when learner nurses realise that the learning content with which they must engage in order to qualify as professional nurses is heavily laden, requires cognitive skills and is not just about acquiring affective and psychomotor nursing skills. Piper ${ }^{[35]}$ calls this a non-cognitive element of perseverance in the programme where learner nurses realise that their chosen career is more academically extensive and rigorous than they had expected, and that not every Tom, Dick and Harry from the street can become a "nurse". Nurse educators in this study 
expressed that political, economic, and social factors force learner nurses to take up nursing for survival while having a negative attitude as they face stresses of unemployment after high school, yet negative attitude is compounded by a negative societal attitude towards nursing. Negative attitudes have an impact on the quality of learner nurses' learning, and this, in turn, impacts negatively on the quality of the delivery process of the content laden curriculum.

\section{IMPLICATIONS AND RECOMMENDATIONS}

From the findings of this study, it is clear that nurse educators experienced difficulties in delivering the content laden curriculum to learner nurses in class. The identified themes paint a picture that clearly reflects that effective learning of learner nurses is negatively affected which lead to academic failure. The themes indicated that nurse educators had difficulties in delivering the content laden curriculum to learner nurses in a large class which resulted in nurse educators using lecture method which did not facilitate the development of higher order thinking skills. Nurse educators felt compelled to down grade their level of teaching during the delivery of the content laden curriculum in order to accommodate academically underprepared learner nurses which resulted in difficulty achieving the set objectives of the learning content and risking to cater for the academically well prepared, achiever-orientated learner nurses, leaving them less challenged and despondent during the process of content delivery. A lack of prior knowledge of the subject meant there is lack of familiarity with the subject's scientific language, concepts and theory therefore learners have hindered academic development and have difficulty progressing academically. ${ }^{[36]}$ A negative attitude during learning content delivery could impede learners' academic growth and development as they attended classes irregularly, did not engage with the large learning content inside and outside the classroom, and became hostile toward nurse educators and peers. ${ }^{[30]}$

\subsection{Large class}

Nurse educators should effectively and speedily deal with incivility in their large classrooms in order to create an enabling learning environment that facilitates effective delivery of the learning content. ${ }^{[20]}$ A learner guide should be used by nurse educators as an excellent communication tool for notifying learner nurses of the heavily laden learning content in order to facilitate a learner's pre-reading of the content, as well as notify them of the expected classroom behaviours. ${ }^{[8]}$ Authentic constructivist approaches such as team-based learning, case studies, community-based learning approach, co-operative learning approach, experiential learning approach, reflective learning approach, problem- based learning approach, and the Socratic style of teaching that encourage learner participation in a large class, facilitate deep learning and the delivery of the learning content should be employed by nurse educators in order to develop learner nurses' higher-order thinking skills. ${ }^{[8]}$

\subsection{Academically underprepared learner nurses}

The academically underprepared learner nurses already in the nursing programmes should be assisted with making a successful transition from high school to higher education institutions through orientation, transition courses from first-year seminars, learning communities, intrusive advising, intensifying tutoring programmes, supplemental instructions, peer tutoring, study group interactions and summer bridging programmes, study skills workshops, mentoring, learners' support groups, and learner-faculty research. ${ }^{[37]}$ This means that academically underprepared learner nurses need a foundational bridging programme to prepare them for higher education, which will result in them performing better with effective delivery of the learning content.

\subsection{Lack of prior knowledge}

Nurse educators should use advance organisers in order to link prior knowledge and new knowledge in a lecture through clarifying information known to learners and preparing the learners for the heavily laden learning content about to be delivered to them. ${ }^{[5]}$ A one-year, stand-alone support bridging programme which should cover English language, Biology, computer literacy and study skills should be introduced particularly as these are important subjects and programmes that will facilitate development of prior knowledge therefore improve the delivery of the learning content in nursing. ${ }^{[38]}$

\subsection{Negative attitude}

Chabeli ${ }^{[39]}$ advocated for the development of a reflective adolescent learner nurse in order to develop their autonomy in learning, critical awareness and knowledge of self, hence developing a positive attitude toward the profession. Support from Centre for Psychological Services and Career Development (PsyCaD) should be provided in order to support learner nurses academically, socially and psychologically, facilitate their interest, motivation and positive attitude and thus improve their chances of academic success.

\section{LIMITATIONS OF THE STUDY}

The study provided rich discussions on the challenges experienced by nurse educators on the delivery of heavily laden learning content at a nursing college in Gauteng. It therefore lacks generalizability to other nursing colleges as these were unique experiences, unless replication of the study by other interested researchers is conducted. Only the experiences of 
nurse educators were explored and described and not those of learner nurses in their classroom. It is recommended that the challenges experienced by learner nurses on the delivery of heavily laden learning content at a nursing college in Gauteng be explored.

\section{Conclusion}

The findings in this study indicated that the challenges that nurse educators face with the delivery of heavily laden learning content are complex and multifactorial. However, there is also a dire need for nurse educators to revise, restructure and reform the content laden curriculum by identifying the essential learning content from the non-essential, as well as remove the repetitive learning content in order to facilitate the delivery process of the content laden curriculum and pro- mote meaningful learning. The need to cover the learning content should not supersede effective teaching and meaningful learning for the development of higher-order thinking skills in learner nurses. Through reflective, interactive pedagogical strategies and effective use of technology and its devices, higher-order thinking skills in learner nurses will be developed and learner nurses will become the self-directed lifelong learners required for the global nursing care of the complex disease profiles in the 21 st century. The nursing curriculum learning content must "reflect the dynamic changes of today's health care system".[10] Therefore nurses entering the field will be equipped with knowledge and skills to adapt to the dynamic global healthcare environment.

\section{CONFlicts OF INTEREST Disclosure}

The author declares that there is no conflict of interest.

\section{REFERENCES}

[1] South Africa. Department of Health. The National Strategic Plan for Nursing Education, Training and Practice 2012/13-2016/17. Pretoria: Government Printers; 2013.

[2] Shisana O, Rehle T, Simbayi LC, et al. South African National HIV Prevalence, Incidence and Behaviour Survey, 2012. Cape Town: Human Sciences Research Council Press; 2014.

[3] South African Nursing Council. [SANC]. Regulations relating to the approval of and the minimum requirements for the education and training of a Nurse (General, Psychiatric and Community) and Midwife leading to registration: Regulation 425 of 1985 (as amended). Pretoria: Government Printers; 1985.

[4] Bezuidenhout M, Human S, Lekhuleni $M$. The new nursing qualifications framework. Trends in Nursing. 2013; 1(1).

[5] Hughes SJ, Quinn FM. Quinn's principles and practice of nurse education. 6th ed. Hampshire, UK: Cengage Learning; 2013.

[6] Giddens JF, Brady DP. Rescuing nursing education from content saturation: The case for a concept-based curriculum. Journal of Nursing Education. 2007; 46(2): 65-69. PMid: 17315564

[7] Pompey JW. Evaluating the student learning and teacher effectiveness in adult health nursing utilizing a jeopardy game. Review of Higher Education \& Self-Learning. 2013; 5(17): 82-86.

[8] Ndawo MG. Factors influencing nurse educators' teaching and learning performance at a nursing college in Gauteng. [master's thesis]. [Auckland Park]: University of Johannesburg; 2014. 335.

[9] Benner P, Sutphen M, Leonard V, et al. Educating nurses: A call for radical transformation. San Francisco: Jossey-Bass; 2009.

[10] Stanley MC, Dougherty JP. A paradigm shift in Nursing Education: A new model. Nursing Education Perspectives. 2010; 31(6): 378-380. PMid:21280445

[11] Oxford Advanced Learner's Dictionary. Oxford Advanced Learner's Dictionary International Student's Edition. 7th ed. New York: Oxford University Press; 2005.

[12] Burns N, Grove SK. The practice of nursing research: Appraisal, synthesis, and generation of evidence. 6th ed. St. Louis: Saunders; 2009.

[13] South Africa. Nursing Act, Act no. 33 of 2005. Pretoria: Government Printers; 2005

Published by Sciedu Press
[14] Stokowski LA. Overhauling nursing education. Medscape; 2011.

[15] Creswell JW. Research design: Qualitative, quantitative, and mixed methods approaches. 3rd ed. Thousand Oaks, CA: Sage Publications; 2009.

[16] Lincoln YS, Guba EG. Naturalistic inquiry. Beverly Hills, CA: Sage; 1985.

[17] Tripod. Effective teaching and learning in large classes, n.d. 2015 Available from: http://breda-guide.tripod.com/News-5.h tm

[18] Cuseo J. The empirical case against large class size: Adverse effects on the teaching, learning, and retention of first-year students. Journal of Faculty Development. 2007; 21(1): 5-21.

[19] Kerr A. Teaching and learning in large classes at Ontario Universities: An exploratory study. Toronto: Higher Education Quality Council of Ontario; 2011.

[20] Knepp KAF. Understanding student and faculty incivility in Higher Education. The Journal of Effective Teaching. 2012; 12(1): 32-45.

[21] Persky AM. The Impact of Team-Based Learning on a Foundational Pharmacokinetics Course. American Journal of Pharmaceutical Education. 2012; 76(2):

[22] Billings DM, Halstead JA. Teaching in nursing: A guide for faculty 4th ed. St. Louis: Elsevier Saunders; 2012.

[23] Miller MA, Murray C. Advising academically underprepared students. NACADA Clearinghouse of Academic Advising Resources. 2005.

[24] South Africa. Council on Higher Education. A proposal for undergraduate curriculum reform in South Africa: The case for a flexible curriculum structure. Report of the Task Team on Undergraduate Curriculum Structure. Pretoria: CHE, 2013.

[25] Roksa J, Calcagno JC. Making the transition to four-year institutions: Academic preparation and transfer (CCRC Working Paper No. 13). New York: Columbia University, Teachers College. Community College Research Center, 2008.

[26] Mthethwa N. How could I have failed varsity? Mail \& Guardian (Online Ed.). 2013.

[27] Ofori R. Age and "type" of domain specific entry qualifications as predictors of student nurses' performance in biolog- 
ical, social and behavioural sciences in nursing assessments. Nurse Education Today. 2000; 20(4): 298-310. PMid:10827101 http://dx.doi.org/10.1054/nedt.1999.0396

[28] Ausubel DP, Novak JD, Hanesian H. Educational psychology: A cognitive view. 2nd ed. New York: Holt, Rinehart and Winston, 1978.

[29] Tsai MT, Tsai LL. The critical success factors and impact of prior knowledge to nursing students when transferring nursing knowledge during nursing clinical practice. Journal of Nursing Management. 2005; 13(6): 459-466. PMid:16238686 http://dx.doi.org/10. 1111/j.1365-2934.2005.00519.x

[30] Tayebi Z, Dehghan-Nayeri N, Negarandeh R, et al. Motives for entering nursing in Iran: A qualitative study. Iranian Journal of Nursing and Midwifery Research. 2013; 18(1): 59-64. PMid:23983730

[31] Maurer T, Allen D, Gatch D, et al. Students' academic motivations in allied health classes. The Internet Journal of Allied Health Sciences and Practice. 2012; 10(1): 1-12.

[32] Breier M, Wildschut A, Mgqolozana T. Nursing in a new era: the profession and education of nurses in South Africa. Cape Town: Human Sciences Research Council Press; 2009.

[33] South Africa. Nursing opportunities for Gauteng job seekers. South African Government News Agency (Online Ed.). 2012 March 14:
South Africa Sect. (col. 1).

[34] Wright S, Maree J. First year Baccalaureate nursing students: Reasons for drop-out? South African Journal of Higher Education. 2007; 21(5): 596-609.

[35] Piper L. No nursing student left behind: Non-cognitive screening. [dissertation] [Glassboro (NJ)]: Rowan University; 2012. 176.

[36] Gresty KA, Cotton DRE. Supporting biosciences in the nursing curriculum: development and evaluation of an online resource. Journal of Advanced Nursing. 2003; 44(4): 339-349. PMid:14651706 http://dx.doi.org/10.1046/j.0309-2402.2003.02813.x

[37] Kuh GD, Kinzie J, Buckley JA, et al. What Matters to Student Success: A Review of the Literature. Commissioned Report for the National Symposium of Postsecondary Student Success: Spearheading a Dialog on Student Success. National Postsecondary Education Commission, 2006.

[38] National Advisory Council on Innovation. [NACI]. Tertiary education costs and other barriers affecting the entry of female students to tertiary education: science, engineering and technology degrees. Pretoria: NACI, 2011.

[39] Chabeli MM. Higher order thinking skills competencies required by outcomes-based education from learners. Curationis. 2006; 29(3): 7886. http://dx.doi.org/10.4102/curationis.v29i3.1107 